3 Research Square

\title{
Elevated Liver Enzymes and Incident Type Two Diabetes Mellitus Risk in Yemeni Patients
}

\section{Lotfi S. Bin Dahman ( $\nabla$ lotfydahman@hu.edu.ye )}

College of Medicine and Health Sciences, Hadhramout University

Omer M. Barahman

College of Medicine and Health Sciences, Hadhramout University

Mariam A. Humam

College of Medicine and Health Sciences, Hadhramout University

Nabil S. Musiaan

College of Medicine and Health Sciences, Hadhramout University

Ahmed M. Daakik

College of Medicine and Health Sciences, Hadhramout University

\section{Research Article}

Keywords: Liver enzymes, type 2 diabetes, Yemeni patients

Posted Date: January 22nd, 2021

DOI: https://doi.org/10.21203/rs.3.rs-152758/v1

License: (c) (i) This work is licensed under a Creative Commons Attribution 4.0 International License. Read Full License 


\section{Abstract}

Liver disease is a major cause of morbidity and mortality in patients with type two diabetes mellitus (T2DM). This case-control study was aimed to assess the association between liver enzymes and incident T2D in Yemeni patients. The present study comprising 142 T2D patients and 142 healthy control subjects were recruited from the diabetic outpatient clinic of Ibn-Sina hospital in Mukalla during the period from $1^{\text {st }}$ January to $30^{\text {th }}$ May 2020. Serum fasting blood glucose (FBG), total cholesterol, triglyceride, high-density lipoprotein cholesterol (HDL-C), alanine aminotransferase (ALT), aspartate aminotransferase (AST), and gamma-glutamyl transferase (GGT) were analyzed using the Cobas Integra Plus 400 autoanalyzer. Also, anthropometric and blood pressure measurements were taken from each participant. T2D patients had significantly higher FBG $(P=<0.0001)$, total cholesterol $(P=<0.0001)$, LDL-C $(P=<0.0001)$, and GGT $(P=<0.0001)$ while, HDL-C was significantly lower in T2D patients $(P=0.021)$. In correlation analysis, serum GGT levels were positively associated with systolic BP $(\mathrm{r}=0.134 ; P=0.025)$, diastolic BP $(r=0.218 ; P=<0.001)$, FBG $(r=0.216 ; P=<0.0001)$, total cholesterol $(r=0.196 ; P=0.0001)$, triglyceride ( $\mathrm{r}=0.123 ; P=0.038)$, and LDL-C ( $\mathrm{r}=0.209 ; P=<0.0001)$. Also, serum ALT and GGT levels were significantly associated with increased incident T2D risk ( $P=0.006$ for ALT and 0.022 for GGT) and the odds ratio at $95 \% \mathrm{Cl}$ comparing highest versus lower tertiles of ALT and GGT were 2.75(2.01-3.48) and 1.17(1.83-6.42) respectively. In conclusion, higher levels of ALT and GGT are positively associated with increased blood glucose levels and may be used as the predictive biomarkers in developing higher risk of diabetes. Thus, routine screening of ALT and GGT in T2D patients is recommended for the early detection of liver disorders.

\section{Introduction}

Diabetes mellitus is a metabolic disorder characterized by chronic hyperglycemia which results from defective insulin action and secretion or both [1]. World Health Organization projects that the number of diabetic patients will exceed 350 million by 2030 [1]. Previous data have documented liver disease is a major cause of morbidity and mortality of type 2 diabetes patients [2-3]. It is well known that the liver is a vital organ in the metabolism of carbohydrates and in maintaining glucose homeostasis during fasting and postprandial period $[2,4]$.

Research indicates that diabetes is associated with a number of liver diseases. Non-alcoholic fatty liver disease (NAFLD) is the scope of chronic liver disease in patients T2D [5], which is characterized by excess deposition of fat in the liver and associated with hepatic insulin resistance (IR) [3] and T2D risk [5]. Serum alanine aminotransferase (ALT) and gamma-glutamyl transferase (GGT) has been shown to be good biomarkers of NAFLD. ALT has been considered the specific marker of liver injury, as found in high concentrations in hepatocytes [6], while GGT is present on the surface of most cell types and highly active in the liver, pancreas, and kidneys [7]. Besides, GGT is responsible for the extracellular glutathione catabolism and may be linked to oxidative stress [8] and chronic inflammation [9]; both oxidative stress 
and chronic inflammation are important pathways for hepatic IR and subsequently T2D development [10].

Many studies on liver enzymes and incident T2D risk were conducted in Europe [11-14] and Asian population [15-21]. However, inconsistent findings are reported: some studies shown that GGT and ALT are significantly associated with improved T2D prediction [15, 21], while others did not [20]. Therefore, we hypothesized that liver is the primary organ are more susceptible to the effects of hyperglycemia-induced oxidative stress, which may lead to liver injury and subsequently chronic inflammation. To our knowledge, there are no previous studies addressing the association between liver enzymes and T2D risk in Yemen Hence, this present study was aimed to assess the association between these liver enzymes and T2D risk in a sample of Yemeni patients.

\section{Subjects And Methods}

\subsection{Study Design and Subjects Selection}

This case-control study was carried out at the College of Medicine and Health Sciences, Hadhramout University, and the subjects were recruited from the diabetic outpatient clinic of Ibn-Sina hospital, Mukalla during the period from $1^{\text {st }}$ January to $30^{\text {th }}$ May 2020. A total of 284 Yemeni adult subjects, randomly selected, and recruited into this study. At recruitment, an in-person interview was conducted using a structured questionnaire to collect health-related information. The study group was subdivided into two groups: 142 healthy control subjects composed of 51 males and 91 females (age: $46.0 \pm 7.94$ yr.), and 142 T2D patients composed of 64 males and 78 females (age: $54.0 \pm 8.29 \mathrm{yr}$.). T2D patients were those who reported being diagnosed with T2D. Healthy control subjects were selected from the remaining participants who were free of T2D and were matched for age, sex, and dialect group with cases on a 1:1 ratio. Moreover, the selected healthy control subjects were screened for the presence of undiagnosed T2D at the time of blood donation by measuring fasting blood glucose (FBG). Healthy control subjects with FBG $\geq 7.0 \mathrm{mmol} / \mathrm{L}$ were excluded from the study. Written consent was obtained from each participant entered into the study. The study was approved by the Ethics Committee of the Medicine and Health Sciences College, Hadhramout University, Mukalla, Yemen. Patients with co-morbidities such as chronic liver disease, chronic renal disease, cardiovascular disease, and malignancy were excluded.

\subsection{Data Collection}

A questionnaire form focusing on demographic information and diabetes history was given to all subjects. The patient's demographic information, clinical presentation, medical history, and physical findings were taken from each subject. This included the patient's age, sex, smoking status (never, current or past), hypertension status (yes or no), diabetes status (yes or no) diabetes duration (years), diabetes medication, and diabetes complications. Patients were diagnosed with diabetes based on medical history, present intake of diabetes medications, or according to the American Diabetes Association (ADA) 
criteria [22]. Classification of Body Mass Index (BMI) was based on the World Health Organization (WHO) [23].

\subsection{Anthropometric and Blood Pressure Measurements}

Weight and height were measured following measured according to WHO guidelines [23]. Body mass index (BMI) was calculated as weight/height ${ }^{2}\left(\mathrm{Kg} / \mathrm{m}^{2}\right)$. Obese subjects were defined as $\mathrm{BMI} \geq 30 \mathrm{~kg} / \mathrm{m}^{2}$ and normal-weight subjects having a BMI of $18-25$. Patients who had a blood pressure of $\geq 140 / 90$ $\mathrm{mmHg}$ or were taking antihypertensive medications were diagnosed with hypertension [24]. A true healthy normal ALT level ranges from 29 to $33 \mathrm{IU} / \mathrm{I}$ for males, and 19 to $25 \mathrm{IU} / \mathrm{I}$ for females and levels above this should be assessed as described by the American College of Gastroenterology (ACG) [25].

\subsection{Biochemical Investigations}

Ten millilitres of the venous blood sample was obtained from consenting subjects. The blood samples were collected by vein puncture in tubes without anticoagulant. The blood samples were then transported to the laboratory immediately. The serum was separated and stored at $-20^{\circ} \mathrm{C}$ freezers till analyses. The serum samples of matched case-control pairs were randomly placed next to each other with the case/control status blinded to the laboratory personnel and were processed, and tested in the same batch. All laboratory equipment was calibrated. Thawing freezing was avoided by dividing the samples into aliquots. Plasma fasting blood glucose (FBG), total cholesterol, triglycerides, and HDL-cholesterol (HDL-C) were determined enzymatically using a chemical autoanalyzer (Cobas Integra 400 Plus, Roche diagnostic $\mathrm{GmbH}$, Mannheim, Switzerland), following the standard procedures as described by the manufacturer. Concentrations of LDL-cholesterol (LDL-C) were calculated using Friedwald's formula [26]. All biochemical investigations were analyzed in the National Center for Public Health Labs-Mukalla, Yemen.

\subsection{Statistical Analysis}

Data were analyzed using the Statistical Package for the Social Sciences for Windows (version 24) and are expressed by mean \pm standard deviation (SD) for continuous variables (normally distributed). Noncontinuous variables are expressed by median (inter-quartile range) and $n$ (percentage) for categorical variables. Independent Student's t-test used for normally distributed continuous variables and Wilcoxon signed-rank test for skewed continuous variables. The Pearson correlation test was performed with ALT, AST, and GGT as the dependent variables. ALT, AST and GGT were divided into tertiles according to their distribution in the healthy control samples and the lowest tertile was served as the reference group. We used conditional logistic regression to model their associations with T2D adjusting for age (continuous), smoking (never, current and past smoker) and BMI (continuous) (model 1). Model 1 plus adjusted total cholesterol ( $\mathrm{mmol} / \mathrm{L})$, triglyceride ( $\mathrm{mmol} / \mathrm{L}), \mathrm{HDL}-\mathrm{C}(\mathrm{mmol} / \mathrm{L})$, and LDL-C ( $\mathrm{mmol} / \mathrm{L})$ (all in tertiles). We repeated the same analysis in 176 cases and control pairs with baseline $\mathrm{FBG}<7.0 \mathrm{mmol} / \mathrm{L}$. Conditional regression analyse was done to estimate the odds ratios (ORs) and 95\% Cls for T2D patients. The 
statistical analysis was conducted at a $95 \%$ confidence level and a $P$-value $<0.05$ was considered statistically significant.

\section{Results}

Descriptive statistics of anthropometric and biochemical data of the study population are presented in table 1. T2D patients had significantly increased BMI $(P=0.008)$, systolic $\mathrm{BP}(P=<0.0001)$, diastolic BP $(P=<0.0001)$, FBG $(P=<0.0001)$, total cholesterol $(P=<0.0001)$, LDL-C $(P=<0.0001)$, and GGT $(P=0.016)$ as compared to healthy control subjects. No significant difference was found in serum triglyceride $(P=$ $0.097)$ and $\operatorname{ALT}(P=0.07)$. Healthy control subjects had significantly increased HDL-C $(P=0.021)$ and AST ( $P=0.001$ ) as compared to T2D patients. On the other hand, 31.7\% of T2D patients had hypertension, whereas, $6.3 \%$ of healthy control subjects had hypertension. Besides, in T2D patients, the current smokers were $4.2 \%$ and the former smokers were $3.5 \%$. According to BMI criteria, $38.7 \%$ of T2D patients had overweight and $24.6 \%$ with obese as compared to healthy control subjects $(40.1 \%, 14.1 \%)$ respectively.

Pearson correlation using ALT, AST, and GGT as dependent variables is presented in table 2. Serum ALT was positively associated with FBG $(\mathrm{r}=0.145, P=0.014)$, triglyceride $(\mathrm{r}=0.172, P=0.004)$, AST $(\mathrm{r}=590, P=$ $<0.001)$, and GGT ( $r=0.507, P=<0.001)$ respectively. Serum GGT was positively associated with systolic $\operatorname{BP}(\mathrm{r}=0.134, P=0.024)$, diastolic BP $(\mathrm{r}=0.218, P=<0.001)$, FBG $(\mathrm{r}=0.216, P=<0.0001)$, total cholesterol ( $\mathrm{r}=0.196, P=0.0001)$, triglyceride $(\mathrm{r}=0.123, P=0.038)$, LDL-cholesterol $(\mathrm{r}=0.209, P=<0.0001)$, and AST ( $r=0.366, P=<0.0001)$ across the combined group.

Using partial correlation analysis (table 3), controlling for age and BMI, significant positive association between ALT with AST $(r=0.589, P=<0.0001)$ and ALT $(r=0.514, P=<0.0001)$ remained significant across the combined group, whilst, the association between ALT with FBG and triglyceride was no longer significant. Using the same analysis, the association between GGT with systolic $B P(r=0.124, P=0.038)$, diastolic BP $(r=0.213, P=<0.0001)$, FBG $(r=0.213, P=<0.0001)$, total cholesterol $(r=0.199, P=0.001)$, triglyceride $(\mathrm{r}=0.127, P=0.033)$, and LDL-C $(\mathrm{r}=0.208, P=<0.0001)$ remained significant before and after age and BMI as adjustment.

The association between liver enzymes and incident T2D risk are presented in table 4. Higher ALT and GGT levels were associated with higher T2D risk (OR comparing extreme tertiles $2.75(95 \% \mathrm{Cl} 2.01$ to $3.48, P=0.006 ; 1.17(95 \% \mathrm{Cl} 1.83$ to $6.42, P=0.022$ respectively) in the final model. While, AST levels showed no significant association both in model 11.02 ; (95\% $\mathrm{Cl} 0.23$ to 4.22, $P=0.550)$ and model 2 1.22(0.02 to 4.79, $P=0.306$ ). In contrast, ALT and GGT levels showed no significant association among case-control pairs with FBG $<7.0 \mathrm{mmol} / \mathrm{L}$, while, higher AST levels were positively associated with increased T2D risk among case-control with FBG $<7.0 \mathrm{mmol} / \mathrm{L}$ in the final model (OR comparing highest versus lowest tertile $1.578(95 \% \mathrm{Cl} 2.718$ to $3.466, P=0.023)$.

\section{Discussion}


Despite the incidence of diabetes is increasing worldwide and its prevalence is higher in developing countries, no studies have examined the relationship between elevated liver enzymes and T2D risk in Yemeni patients. Our study therefore was focused on hepatocytes as the vital organ contributing in glucose homeostasis during fasting and postprandial stage. Serum ALT, AST, and GGT were taken from each participant and used for this work. Additionally, most people aged $\geq 45$ years in developing countries suffer from diabetes [27]. These findings were convenient with our study showed that T2D patients had significantly higher mean age compared to healthy control subjects (Table 1).

Besides, our present findings also observed significantly increased BMI, systolic BP, and diastolic BP in T2D patients than healthy control subjects. The present findings also showed that serum FBG, total cholesterol, and LDL-C were significantly higher in T2D patients than healthy control subjects, while, no significantly difference was found among both groups for serum triglyceride. In contrast, HDL-C was significantly lower in T2D patients. Our study further revealed higher levels of GGT in T2D patients. While, AST was significantly lower in T2D patients. Besides, no significantly difference was found among both groups for ALT.

Our study also revealed positive correlations between GGT with FBG, total cholesterol, triglyceride, and LDL-C across the combined group before and after adjustment for age and BMI, whilst, the association between ALT with FBG and triglyceride was no longer significant after adjustment for age and BMI. Such a positive relationship between liver enzymes and blood lipids profile in T2D patients has been observed in previous studies [4,28-31]. This finding supports the role of hepatic IR in the pathogenesis of NAFLD in patients with T2D [6,32]. Moreover, Cho et al. reported a correlation between ALT activity and increased fatty liver [16]. The impairment of the normal process of synthesis and elimination of triglycerides may progress to fibrosis, cirrhosis, and hepatocellular carcinoma [33-34]. Triglyceride is a major form of lipids stored in the liver of patients with NAFLD.

In addition to its effect on lipid metabolism, insulin also contributes a proinflammatory effect to liver abrasion [35]. Thus, inflammation contributes to hepatic IR. Additionally, pro-inflammatory cytokines and transcription factors are highly expressed in white adipose tissue and liver. Obesity is defined as a state of chronic low-grade inflammation and a highly risk factor for hepatic IR and NAFLD. Thus, it is a primary cause of decreased insulin sensitivity. Obesity leads to lipid accumulation and activates the c-Jun Nterminal kinase (JNK) and nuclear factor-kappa B (NF-kB) signaling pathways, which consequently increase production of pro-inflammatory cytokines, such as tumor necrosis factor-alpha (TNF-a) and interleukin-6 (IL-6) [36]. In addition, various adipose tissue-derived proteins, such as adiponectin and leptin, are considered to be major links between obesity, hepatic IR and related inflammatory disorders [37].

GGT is known as a marker of hepatobiliary disorders and is associated with other pathological conditions like diabetes. Free radicals generated by diabetes consume glutathione which induces the increased expression of GGT in hepatocytes. Various studies have suggested the association of GGT concentrations with T2D [38-41] and hyperlipidemia [42]. These findings are in agreement with our study; GGT was 
significantly associated with the hyperglycemic and hyperlipidemic profile. We observed ALT and GGT together were positively correlated. Moreover, some data also reported elevated GGT levels with ALT in T2D patients with dyslipidemia [39-40, 43]. Although we did not confirm the presence of fatty liver by ultrasound techniques, we showed the relationship of ALT, AST, and GGT with the predictors of diabetes and lipid profile parameters, presenting hepatocellular injury.

A study of male Korean workers found that AST was independently associated with diabetes [44], while in a study of male Japanese office workers AST was not associated with T2D risk [40]. Some studies also reported that ALT is a significant predictor of diabetes while AST is not [45]. These findings are in agreement with our findings as AST does not show considerable relationship with the studied parameters. Besides, Clark et al. also suggested that mild or chronic elevations of these aminotransferases may be due to NAFLD [46-47]. However, our study is limited to the standard method of liver biopsy for the prediction of NAFLD but it goes with the analysis of the Third National Health and Nutritional Examination Survey where individuals with NAFLD are known to have elevated aminotransferases.

In addition, our study also found that increased ALT and GGT levels improve prediction of T2D risk, and this was supported by several previous studies: a meta-analysis reported a pooled relative risk of 1.34 (95\% $\mathrm{Cl} 1.27$ to 1.42) comparing highest versus lowest tertiles of GGT levels [48] and 1.66 (95\% $\mathrm{Cl} 1.31$ to 2.09) for ALT [49]. Besides, a case- control study in a Chinese population also reported higher levels of ALT and GGT with increased risk of T2D 2.00 (1.01 to 3.96; ALT) and 2.38 (1.21 to 4.66; GGT) [21]. A Mendelian randomization study further provided an evidence for the relationship between higher GGT levels and hepatic IR study [50]. In contrast, our study did not observe any relationship of AST incident T2D risk, which was consistent with previous studies [18, 30, 38, 51], and this may be due to lack of specificity of AST for liver diseases [18]. However, one Korean study showed positive correlation between GGT/ALT and T2D risk among patients without fatty liver, suggesting alternative pathways exist [17]. Thus, increased GGT and ALT levels were linked to T2D development as surrogate measures of NAFLD [52]. NAFLD also, may indicate fat deposition in other organs such as skeletal muscle, the myocardium, and the pancreas, which predispose individuals to T2D risk [52]. Moreover, research evidence showed that the relations of GGT and ALT with T2D risk were also independent of other important pathologies in T2D development such as whole-body insulin resistance [3, 45$]$ and blood lipids profile [3, 14-16].

The strength of the present study included adjustment for well-established diabetes risk factors including $\mathrm{BMI}$, blood lipids, and hypertension, and using comprehensive statistical methods (Pearson correlation coefficient and regression analysis) to explore the predictive utility of liver enzymes with other risk factors. However, there are some limitations. First, our sample size may be small and thus underpowered to detect the interaction with ALT and GGT. Second, we measured liver enzymes only once and may not represent long-term profile. Third, we did not measure hepatitis B and $C$ infection, which could result in elevated liver enzymes. Fourth, we did not measure insulin, CRP, leptin, and adiponectin as predictive biomarkers links between obesity, hepatic IR and related inflammatory disorders in T2D patients. Thus, further large sample size with measurement of insulin, hs-CRP, leptin, adiponectin, and interleukins are 
required to confirm these correlations. In conclusion, increased levels of ALT and GGT are positively associated with higher risk of T2D in Yemeni patients. Thus, routine screening of liver enzymes in T2D patients is recommended for the early detection of liver abnormalities.

\section{Conclusions}

Increased levels of ALT and GGT are positively associated with higher risk of T2D in Yemeni patients, and may be used as the predictive biomarkers in developing T2D risk. Thus, routine screening of ALT and GGT in T2D patients is recommended for the early detection of liver abnormalities.

\section{Declarations}

Data Availability

All requests for data access should be addressed to the corresponding author. Proposals requesting data access will have to specify how they plan to use the data.

Conflicts of Interest

The authors declare no conflicts of interest.

Acknowledgments

The authors are grateful to Al-Huda Medical Agency, Mukalla, Yemen, for funding the study and the IbnSina Hospital, Mukalla, Yemen for technical support. Also, we are thankful to the physicians and nurses who recruited and collected the data of the participants. Special thanks to Students of Medical Laboratory Sciences Department (Ali Alqaaiti, Saleh Daiban, Sabri Barafah, Afaf Aldibani, Safa Basawaid, and Noor Zahfan) for sample collection and analysis and data entry. Special thanks to Ms. Nasiba AlAidros for the statistical analysis.

\section{References}

1. World Health Organization, Definition, diagnosis and classification of diabetes mellitus and its complications: Report of a WHO consultation. Geneva: World Health Organization, 1999.

2. Gavin and A.S.T. Levinthal, "Liver disease and diabetes mellitus," Clin Diabetes, vol. 17, 1999.

3. J. Hanley, K. Williams, A. Festa et al., "Elevations in marker of liver injury and risk of type 2 diabetesThe insulin resistance atherosclerosis study," Diabetes, vol. 53, pp. 2623-2632, 2004. https://doi.org/10.2337/diabetes.53.10.2623.

4. Al-Jameil, F.A. Khan, S. Arjumand et al., "Associated liver enzymes with hyperlipidemic profile in type 2 diabetes patients," Int J Clin Exp Pathol, vol. 7, pp. 4345-4349, 2014.

5. Ballestri, S. Zona, G. Targher et al., "Nonalcoholic fatty liver disease is associated with an almost twofold increased risk of incident type 2 diabetes and metabolic syndrome. Evidence from a 
systematic review and meta-analysis," J Gastroenterol Hepatol, vol. 31, pp. 936-944, 2016. https://doi.org/10.1111/jgh.13264.

6. G. Tolman, V. Fonseca, A. Dalpiaz et al., "Spectrum of liver disease in type 2 diabetes and management of patients with diabetes and liver disease," Diabetes Care, vol. 30, pp. 734-743, 2007.

7. G. Giannini, R. Testa and V. Savarino, Liver enzyme alteration: a guide for clinicians," CMAJ, vol. 172, pp. 367-379, 2005. https://doi.org/10.1503/cmaj.1040752.

8. H. Hanigan and H.F. Frierson, Jr., "Immunohistochemical detection of gamma-glutamyl transpeptidase in normal human tissue," J Histochem Cytochem, vol. 44, pp. 1101-1108, 1996. https://doi.org/10.1177/44.10.8813074.

9. Turgut and I. Tandogan, "Gamma-glutamyltransferase to determine cardiovascular risk: shifting the paradigm forward," J Atheroscler Thromb, vol. 18, pp. 177-181, 2011. https://doi.org/10.5551/jat.6189.

10. H. Lee and D.R. Jacobs, Jr., "Association between serum gamma-glutamyltransferase and C-reactive protein," Atherosclerosis, vol. 178, pp. 327-330, 2005. https://doi.org/10.1016/j.atherosclerosis.2004.08.027.

11. Fraser, R. Harris, N. Sattar et al., "Alanine aminotransferase, gama-glutamyltransferase, and incident diabetes: the British Women's Heart and Health Study and meta-analysis," Diabetes Care, vol. 32, pp. 741-750, 2009.

12. Goessling, J.M. Massaro, R.S. Vasan, et al., "Aminotransferase levels and 20-year risk of metabolic syndrome, diabetes, and cardiovascular disease," Gastroenterology, vol. 135, pp. 1935-44, 44.e1, 2008.

13. Monami, G. Bardini, C. Lamanna et al., "Liver enzymes and risk of diabetes and cardiovascular disease: results of the Firenze Bagno a Ripoli (FIBAR) study," Metab Clin Exp, vol. 57, pp. 387-392, 2008.

14. Sattar, O. Scherbakova, I. Ford et al., "Elevated alanine aminotransferase predicts new-onset type 2 diabetes independently of classical risk factors, metabolic syndrome, and C-reactive protein in the west of Scotland coronary prevention study," Diabetes, vol. 53, pp. 2855-2860, 2004.

15. Doi, M. Kubo, K. Yonemoto et al., "Liver enzymes as a predictor for incident diabetes in a Japanese population: the Hisayama study," Obesity (Silver Spring), vol. 15, pp. 1841-1850, 2007.

16. H. Cho, H.C. Jang, S.H. Choi et al., "Abnormal liver function test predicts type 2 diabetes: a community-based prospective study," Diabetes Care, vol. 30, pp. 2566-2568, 2007.

17. H. Kim, J.Y. Park, K.U. Lee, et al., "Association of serum gamma-glutamyltransferase and alanine aminotransferase activities with risk of type 2 diabetes mellitus independent of fatty liver," Diabetes Metab Res Rev, vol. 25, pp. 64-69, 2009.

18. Jiamjarasrangsi, S. Sangwatanaroj, V. Lohsoonthorn, et al., "Increased alanine aminotransferase level and future risk of type 2 diabetes and impaired fasting glucose among the employees in a university hospital in Thailand," Diabetes Metab, vol. 34, pp. 283-289, 2008. 
19. Tohidi, H. Harati, Hadaegh, F., et al., "Association of liver enzymes with incident type 2 diabetes: a nested case control study in an Iranian population," BMC Endocr Disord, vol. 8, 2008.

20. B. Schulze, C. Weikert, T. Pischon et al., "Use of multiple metabolic and genetic markers to improve the prediction of type 2 diabetes: the EPIC-Potsdam Study," Diabetes Care, vol. 32, pp. 2116-2119, 2009.

21. Ye-Li, K. Woon-Puay, Y. Jian-Min and P. An, "Association between liver enzymes and incident type 2 diabetes in Singapore Chinese men and women," BMJ Open Diabetes Research and Care, vol. 4, pp. e000296, 2016. https://doi.org/10.1136/bmjdrc-2016-000296.

22. American Diabetes Association, "Standards of medical care in diabetes-2016," Diabetes Care, vol. 39, pp. 101-106, 2016. https://doi.org/10.2337/dc16-S003.

23. World Health Organization, "Physical status: the use and interpretation of anthropometry (1995) Report of WHO expert committee. WHO Technical Report Series," no. 854. Geneva: WHO, pp. 321344, 1995.

24. V. Chobanian, G.L. Bakris, H.R. Black et al., "Seventh report of the Joint National Committee on Prevention, Detection, Evaluation, and Treatment of High Blood Pressure," Hypertension, vol. 42, pp. 1206-1252, 2003. https://doi.org/10.1161/01.HYP.0000107251.49515.c2.

25. Y. Kwo, S.M. Cohen and J.K. Lim, "ACG clinical guideline: evaluation of abnormal liver chemistries," Am J Gastroenterol, vol. 112, pp. 18-35, 2017. https://doi.org/10.1038/ajg.2016.517.

26. T. Friedewald, R.I. Levy and D.S. Fredrickson, "Estimation of the concentration of low-density lipoprotein cholesterol in plasma, without use of the preparative ultracentrifuge," Clin Chem, vol. 18, pp. 499-502, 1972. https://doi.org/10.1093/clinchem/36.1.15.

27. Nwarfor and A. Owhoji, "The prevalence of diabetes mellitus in port-Harcourt correlates with the socio-economic status," J App/ Sci Environ Mgt, vol. 5, no. 9, pp. 75-77, 2001.

28. R. Jain, V. Shetty, G.S. Singh and S. Shetty, "A Study of Lipid Profile in Diabetes Mellitus," Int J Sci Stud, vol. 4, pp. 56-61, 2016.

29. Han, H.K. Soe and A. Htet, "Determinants of Abnormal Liver Function Tests in Diabetes Patients in Myanmar," Int J Diab Res, vol. 1, pp. 36-41, 2012. https://doi.org/10.5923/j.diabetes.20120103.02.

30. Belay, S. Daniel, K. Tedla and N. Gnanasekaran, "Impairment of liver function tests and lipid profiles in type 2 diabetic patients treated at the diabetic center in Tikur Anbessa specialized teaching hospital (Tasth), Addis Ababa, Ethiopia," J Diabetes Metab, vol. 5, pp. 454, 2014. https://doi.org/10.4172/2155-6156.1000454.

31. A. Adeniran, P.O. Dolapo, A.B. Oluwole, et al., "Liver Enzymes and Lipid Profile Among Type 2 Diabetic Patients in Osogbo, Nigeria," Greener J Med Sci, vol. 3, pp. 174-178, 2013. https://doi.org/10.15580/GJMS.2013.5.011313373.

32. Nannipieri, C. Gonzales, S. Baldi et al., "Liver enzymes, the metabolic syndrome, and incident diabetes: The Mexico City diabetes study," Diabetes Care, vol. 28, pp. 1757-62, 2005. https://doi.org/10.2337/diacare.28.7.1757. 
33. G. Tolman, V. Fonseca, M.H. Tan and A. Dalpiaz, Hepatobiliary disease in type 2 diabetes mellitus," Ann Intern Med, vol. 141, pp. 946-956, 2004. https://doi.org/10.7326/0003-4819-141-12-20041221000011.

34. Chatila and A.B. West, "Hepatomegaly and abnormal liver tests due to glycogenesis in adults with diabetes," Med Balt, vol. 75, pp. 327-333, 1996. https://doi.org/10.1097/00005792-19961100000003.

35. S. Balaji, “Serum alanine transaminases and lipid profile in type 2 diabetes mellitus Indian patient,” $J$ Diab Res, 2014. https://doi.org/10.5171/2013.613176.

36. Sharma, N.K. Vikram, A. Misra et al., "Assessment of 11-beta hydroxysteroid dehydrogenase (11betaHSD1) 4478T\&gt; $G$ and tumor necrosis factor-alpha (TNF-alpha)-308G\&gt; A polymorphisms with obesity and insulin resistance in Asian Indians in North India," Mol Biol Rep, vol. 40, pp. 626170, 2013.

37. Chen, R. Yu, Y. Xiong, F. Du and S. Zhu, "A vicious circle between insulin resistance and inflammation in nonalcoholic fatty liver disease," Lipids in Health and Disease, vol. 16, pp. 203-211, 2017.

38. H. Lee, K. Silventonein, D.R. Jacobs et al., "Gamma glutamyltransferase, obesity and the risk of type 2 diabetes observational cohort study among 20,158 middle aged men and women," J Clin Endocrinol Metab, vol. 89, pp. 5410-5414, 2014. https://doi.org/10.1210/jc.2004-0505.

39. H. Lee, M.H. Ha, J.H. Kim et al., "Gamma glutamyltransferase and diabetes-a four year follow up study," Diabetologia, vol. 46, pp. 359-364, 2003. https://doi.org/10.1007/s00125-003-1036-5.

40. Nakanishi, K. Suzuki and K. Tatara, "Serum gamma glutamyltransferase and risk of metabolic syndrome and type 2 diabetes in middle aged Japanese men," Diabetes Care, vol. 27, pp. 1427-1432, 2004. https://doi.org/10.2337/diacare.27.6.1427.

41. H. Lee, D.R. Jacobs, M. Gross, C.I. Kiefe et al., "Gamma glutamyltransferase is a predictor of incident diabetes and hypertension: the Coronary Artery Risk Development in Young Adults (CARDIA) Study," Clin Chem, vol. 49, pp. 1358-1366, 2003. https://doi.org/10.1373/49.8.1358.

42. Sakuta, T. Suzuki, H. Yasuda and T. Ito, "Gamma glutamyltransferase and airflow obstruction in middle-aged men," Eur J Intern Med, vol. 16, pp. 348-351, 2005.

https://doi.org/10.1016/j.ejim.2005.06.005.

43. Marchesini, M. Brizi, G. Bianchi et al., "Nonalcoholic fatty liver disease: a feature of the metabolic syndrome," Diabetes, vol. 50, pp. 1844-1850, 2011. https://doi.org/10.2337/diabetes.50.8.1844.

44. R. Ahn, H.S. Nam, K.S. Park et al., "The association between liver enzymes and risk of type 2 diabetes: the Namwon study," Diabetol Metab Syndr, vol. 6, pp. 14, 2014. https://doi.org/10.1186/1758-5996-6-14.

45. Vozarova, N. Stefan, R.S. Lindsay et al., "High alanine aminotransferase is associated with decreased hepatic insulin sensitivity and predicts the development of type 2 diabetes," Diabetes, vol. 51, no. 6, pp. 1889-1895, 2002. https://doi.org/10.2337/diabetes.51.6.1889.

46. M. Clark and A.M. Diehl, "Nonalcoholic fatty liver disease: an underrecognized cause of cryptogenic cirrhosis," JAMA, vol. 290, pp. 3000-3004, 2003. https://doi.org/10.1001/jama.289.22.3000. 
47. M. Clark, F.L. Brancati and A.M. Diehl, "The prevalence and etiology of elevated aminotransferase levels in the United States," Am J Gastroenterol, vol. 98, pp. 960-967, 2003. https://doi.org/10.1111/j.1572-0241.2003.07486.x.

48. K. Kunutsor, A. Abbasi and A.I. Adler, "Gamma-glutamyl transferase and risk of type II diabetes: an updated systematic review and dose-response meta-analysis," Ann Epidemiol, vol. 24, pp. 809-816, 2014.

49. K. Kunutsor, T.A. Apekey and J. Walley, "Liver aminotransferases and risk of incident type 2 diabetes: a systematic review and meta-analysis," Am J Epidemiol, vol. 178, pp. 159-171, 2013.

50. Conen, P. Vollenweider, V. Rousson et al., "Use of a Mendelian randomization approach to assess the causal relation of gamma-glutamyltransferase with blood pressure and serum insulin levels," Am J Epidemiol, vol. 172, pp. 1431-1441, 2010.

51. G. Wannamethee, O. Papacosta, P.H. Whincup et al., "The potential for a two-stage diabetes risk algorithm combining non-laboratory-based scores with subsequent routine non-fasting blood tests: results from prospective studies in older men and women," Diabet Med, vol. 28, pp. 23-30, 2001.

52. H. Unger, "Minireview: weapons of lean body mass destruction: the role of ectopic lipids in the metabolic syndrome," Endocrinology, vol. 144, pp. 5159-65, 2003.

\section{Tables}

Table1. Anthropometric and biochemical data of healthy controls and T2D patients 


\begin{tabular}{|c|c|c|c|}
\hline Variables & Healthy controls & T2D patients & $P$-value \\
\hline $\mathrm{N}$ & 142 & 142 & \\
\hline Age (years) & $46.0 \pm 7.94$ & $54.0 \pm 8.29$ & $<0.0001$ \\
\hline Sex: male/female & $51(35.9) / 91(64.1)$ & $63(44.4) / 78(54.9)$ & \\
\hline Weight (kg) & $71.12 \pm 10.67$ & $69.61 \pm 13.83$ & $<0.0001$ \\
\hline Height (cm) & $164.57 \pm 8.47$ & $159.97 \pm 10.04$ & $<0.0001$ \\
\hline $\mathrm{BMI}\left(\mathrm{kg} / \mathrm{m}^{2}\right)$ & $26.31 \pm 3.95$ & $27.21 \pm 4.94$ & 0.008 \\
\hline $\mathrm{SBP}(\mathrm{mmHg})$ & $115.28 \pm 13.11$ & $128.80 \pm 20.92$ & $<0.0001$ \\
\hline $\mathrm{DBP}(\mathrm{mmHg})$ & $70.45 \pm 9.02$ & $79.47 \pm 9.90$ & $<0.0001$ \\
\hline \multicolumn{4}{|l|}{ BMI classification: } \\
\hline Normal weight & $65(45.8)$ & $52(36.6)$ & \\
\hline Overweight & $57(40.1)$ & $55(38.7)$ & \\
\hline Obese & $20(14.1)$ & $35(24.6)$ & \\
\hline \multicolumn{4}{|l|}{ History of hypertension: } \\
\hline Yes/no & $9(6.3) / 133(93.7)$ & $45(31.7) / 97(68.3)$ & \\
\hline \multicolumn{4}{|l|}{ Smoking status: } \\
\hline Never Smoker & $142(100)$ & $131(92.3)$ & \\
\hline Current Smoker & $0(0)$ & $6(4.2)$ & \\
\hline Former Smoker & $0(0)$ & $5(3.5)$ & \\
\hline $\mathrm{FBG}(\mathrm{mmol} / \mathrm{L})$ & $5.18 \pm 0.91$ & $8.91 \pm 2.89$ & $<0.0001$ \\
\hline Total cholesterol (mmol/L) & $4.70 \pm 0.77$ & $5.16 \pm 1.20$ & $<0.0001$ \\
\hline Triglyceride (mmol/L) & $1.24 \pm 0.37$ & $1.16 \pm 0.42$ & 0.097 \\
\hline HDL-C (mmol/L) & $1.67 \pm 0.42$ & $1.57 \pm 0.34$ & 0.021 \\
\hline LDL-C (mmol/L) & $2.77 \pm 0.80$ & $3.35 \pm 1.17$ & 0.001 \\
\hline ALT (IU/L) & $13.1(8.37-19.3)$ & 11.6(7.3-16.8) & 0.07 \\
\hline AST (IU/L) & $21.2(17.8-28.7)$ & 16.4(13.3-21.7) & 0.001 \\
\hline GGT (IU/L) & $25.1(16.8-34.7)$ & $29.2(18.4-49.7)$ & $<0.0001$ \\
\hline
\end{tabular}


BMI, body mass index; SBP, systolic blood pressure; DBP, diastolic blood pressure; FBG, fasting blood glucose; HDL-C, high-density lipoprotein cholesterol; LDL-C, low-density lipoprotein cholesterol; ALT, alanine aminotransferase; AST, aspartate aminotransferase; GGT, gamma-glutamyltransferase.

Table 2. Pearson correlation using ALT, AST and GGT as dependent variables in the combined study group 


\begin{tabular}{|c|c|c|c|c|c|c|}
\hline$N=284$ & ALT & & AST & & GGT & \\
\hline & $r$ & $P$-value & $r$ & $P$-value & $r$ & $P$-value \\
\hline Age (years) & -0.046 & 0.443 & 0.010 & 0.860 & 0.047 & 0.433 \\
\hline $\operatorname{Sex}(M / F)$ & $0.119^{\star}$ & 0.046 & 0.116 & 0.050 & 0.016 & 0.789 \\
\hline Weight (kg) & -0.001 & 0.989 & -0.008 & 0.895 & -0.004 & 0.945 \\
\hline Height (cm) & 0.098 & 0.101 & 0.071 & 0.235 & -0.058 & 0.334 \\
\hline BMI $\left(\mathrm{kg} / \mathrm{m}^{2}\right)$ & -0.070 & 0.241 & -0.059 & 0.326 & 0.033 & 0.538 \\
\hline $\mathrm{SBP}(\mathrm{mmHg})$ & -0.037 & 0.533 & -0.058 & 0.334 & $0.134^{*}$ & 0.024 \\
\hline $\mathrm{DBP}(\mathrm{mmHg})$ & 0.013 & 0.830 & -0.080 & 0.178 & $0.218^{\star \star}$ & $<0.001$ \\
\hline $\mathrm{FBG}(\mathrm{mmol} / \mathrm{L})$ & $0.145^{\star}$ & 0.014 & -0.067 & 0.260 & $0.216^{\star *}$ & $<0.0001$ \\
\hline Total cholesterol (mmol/L) & 0.027 & 0.653 & 0.081 & 0.176 & $0.196^{*}$ & 0.0001 \\
\hline Triglyceride (mmol/L) & $0.172^{\star \star}$ & 0.004 & 0.087 & 0.141 & $0.123^{*}$ & 0.038 \\
\hline $\mathrm{HDL}-\mathrm{C}(\mathrm{mmol} / \mathrm{L})$ & -0.091 & 0.124 & -0.023 & 0.699 & -0.064 & 0.285 \\
\hline LDL-C (mmol/L) & 0.047 & 0.429 & 0.082 & 0.170 & $0.209^{* *}$ & $<0.0001$ \\
\hline $\operatorname{ALT}(I U / L)$ & & & $0.590^{\star *}$ & $<0.0001$ & $0.507^{\star \star}$ & $<0.0001$ \\
\hline AST (IU/L) & $0.590^{\star \star}$ & $<0.0001$ & & & $0.366^{* \star}$ & $<0.0001$ \\
\hline GGT (IU/L) & $0.507^{\star *}$ & $<0.0001$ & $0.366^{\star *}$ & $<0.0001$ & & \\
\hline $\begin{array}{l}\text { Pearson correlation coefficie } \\
\star \star \text { Correlation is significant } \\
\text { * Correlation is significant a }\end{array}$ & 0.01 lev & $\begin{array}{l}\text { onding } p \text {-v } \\
\text { (2-tailed). } \\
\text { (2-tailed). }\end{array}$ & ue $(p<0.0$ & s consider & a signific & \\
\hline \multicolumn{7}{|c|}{ 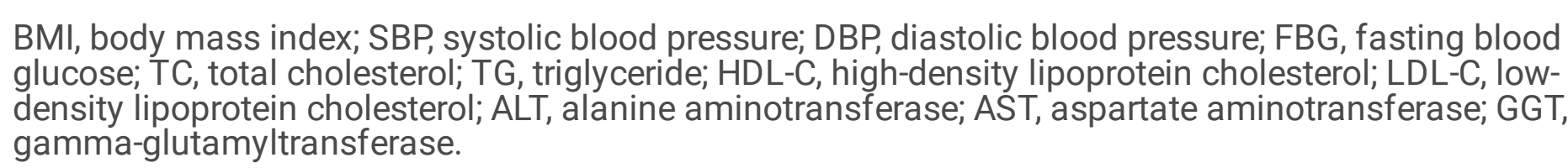 } \\
\hline
\end{tabular}

Table 3: Pearson correlation using ALT, AST and GGT as dependent variables in the combined groups studied after Age and BMI adjustment as a covariance 


\begin{tabular}{|c|c|c|c|c|c|c|}
\hline \multirow[t]{2}{*}{$N=284$} & \multicolumn{2}{|l|}{ ALT } & \multicolumn{2}{|l|}{ AST } & \multicolumn{2}{|l|}{ GGT } \\
\hline & $r$ & $P$-value & $r$ & $P$-value & $r$ & $P$-value \\
\hline $\operatorname{Sex}(M / F)$ & 0.116 & 0.051 & 0.114 & 0.055 & 0.017 & 0.772 \\
\hline $\mathrm{SBP}(\mathrm{mmHg})$ & -0.018 & 0.764 & -0.053 & 0.377 & $0.124^{*}$ & 0.038 \\
\hline $\mathrm{DBP}(\mathrm{mmHg})$ & 0.024 & 0.686 & -0.078 & 0.194 & $0.213^{\star \star}$ & $0<.0001$ \\
\hline FBG (mmol/L) & 0.161 & 0.007 & -0.074 & 0.213 & $0.213^{\star \star}$ & $<0.0001$ \\
\hline Total cholesterol $(\mathrm{mmol} / \mathrm{L})$ & 0.027 & 0.652 & 0.085 & 0.155 & 0.199 & 0.001 \\
\hline Triglyceride (mmol/L) & 0.171 & 0.004 & 0.090 & 0.130 & 0.127 & 0.033 \\
\hline $\mathrm{HDL}-\mathrm{C}(\mathrm{mmol} / \mathrm{L})$ & -0.104 & 0.081 & -0.026 & 0.668 & -0.056 & 0.351 \\
\hline LDL-C (mmol/L) & 0.052 & 0.388 & 0.087 & 0.147 & 0.208 & $<0.0001$ \\
\hline ALT (IU/L) & & & $0.589^{\star \star}$ & $<0.0001$ & $0.514^{\star \star}$ & $<0.0001$ \\
\hline AST (IU/L) & $0.589^{\star *}$ & $<0.0001$ & & & $0.368^{\star \star}$ & $<0.0001$ \\
\hline GGT (IU/L) & $0.514^{\star *}$ & $<0.0001$ & $0.368^{\star *}$ & $<0.0001$ & & \\
\hline $\begin{array}{l}\text { Pearson correlation coeffici } \\
\star * \text { Correlation is significant } \\
\text { * Correlation is significant a }\end{array}$ & $\begin{array}{l}\text { vith corre } \\
\text { e } 0.01 \text { le } \\
0.05 \text { leve }\end{array}$ & $\begin{array}{l}\text { onding } p \text {-v } \\
\text { (2-tailed). } \\
\text { (2-tailed). }\end{array}$ & ue $(p<0.0$ & s significa & & \\
\hline \multicolumn{7}{|c|}{$\begin{array}{l}\text { BMI, body mass index; SBP, systolic blood pressure; DBP, diastolic blood pressure; FBG, fasting blood } \\
\text { glucose; HDL-C, high-density lipoprotein cholesterol; LDL-cholesterol, low-density lipoprotein } \\
\text { cholesterol; ALT, alanine aminotransferase; AST, aspartate aminotransferase; GGT, gamma- } \\
\text { glutamyltransferase. }\end{array}$} \\
\hline
\end{tabular}

Table 4: Odds ratio $(95 \% \mathrm{Cl})$ of T2D associated with different levels of liver enzymes. Data are presented as odds ratio at $95 \%$ confidence intervals. 


\section{Tertiles of Liver enzymes}

Variables

Whole dataset

\section{ALT}

Median (range)

Reference

Controls/T2D

Model 1

Model 2

\section{AST}

Median (range)

Controls/T2D

Model 1

Model 2

GGT

Median (range) 21(7.8-36.9)

Controls/T2D

Model 1

Model 2
T1

T2

T3

$P$-value

$37.5(31-57.7)$

$16 / 11$

$2.57(1.49-3.65)$

0.007

1.02(0.11-1.93)

$2.75(2.01-3.48)$

0.006

$16.7(11.8-25.1) \quad 30.6(25.2-38.5)$

$37 / 17$

1.00(1.23-2.71)

$1.20(1.44-3.28)$

46.3(37.0-66.1)

$36 / 25$

0.95(1.14-2.58)

$1.16(0.65-5.18)$
43.5(38.6-51.8)

$15 / 6$

1.02(0.23-4.22)

0.550

$1.22(0.02-4.79)$

0.306

\section{Limited to cases with baseline FBG $<7.0 \mathrm{mmol} / \mathrm{L}$ and their matched controls}

ALT

Median (range) $\quad 8.3(2.7-15)$

19.7(16-30)

$37.5(31-57.7)$

Controls/T2D 85/31

$35 / 8$

$13 / 2$

Model 1

1

1.366(1.751-3.605)

$1.377(1.936-3.462)$

0.343

Model 2

1

1.353(0.838-4.467)

$1.358(2.555-2.769)$

0.129

\section{AST}

Median (range)

$16.7(11.8-25.1)$

$30.6(25.2-38.5)$

43.5(38.6-51.8)

Controls/T2D

$85 / 34$

$36 / 4$

$12 / 2$

Model 1

$1.287(1.797-3.248)$

1.308(0.161-4.968)

0.111

Model 2

1.570(1.742-4.414)

1.578(2.718-3.466)

0.023 


\section{GGT}

Median (range) $\quad$ 21(7.8-36.9)

46.3(37.0-66.1)

78.7(66.2-101)

Controls/T2D

$105 / 24$

$23 / 9$

$6 / 7$

Model 1

1

1.167(0.368-4.207)

1.196(1.045-5.733)

0.714

Model 2

1

1.422(1.165-4.408)

1.444(0.261-5.922)

0.826

ORs of liver enzymes in the whole dataset and among cases with baseline FBG $(<7.0 \mathrm{mmol} / \mathrm{L})$ and their matched controls were analysed using conditional logistic regression models with adjustment for the following covariates.

Model 1: adjusted for age, BMI, smoking status and history of hypertension (yes/no).

Model 2: model 1 plus adjusted serum total cholesterol (mmol/L), triglycerides (mmol/L), HDL-C $(\mathrm{mmol} / \mathrm{L})$ and LDL-C (mmol/L) (all in tertiles).

FBG, fasting blood glucose; HDL-C, high-density lipoprotein cholesterol; LDL-C, low-density lipoprotein cholesterol; ALT, alanine aminotransferase; AST, aspartate aminotransferase; GGT, gammaglutamyltransferase. 